\title{
Clonal diversity and genomic characterization of Panton-valentine Leukocidin (PVL)-positive Staphylococcus aureus in Tehran, Iran
}

\author{
Zahra Najafi olya ${ }^{1}$, Shahin Najar-Peerayeh ${ }^{1}$, Abbas Yadegar ${ }^{2}$ and Bita Bakhshi ${ }^{1 *}$
}

\begin{abstract}
Background: Some Staphylococcus aureus strains produce Panton-Valentine leukocidin (PVL), a bi-component poreforming toxin, which causes leukocyte lysis and tissue necrosis. Currently, there is very limited information on the molecular epidemiology of PVL-encoding S. aureus strains in Iran. This study aimed to determine the molecular epidemiology and genetic background of PVL-positive S. aureus clinical strains isolated from Iranian patients.

Methods: A total of 28 PVL-positive S. aureus strains were detected from 600 S. aureus isolates between February 2015 and March 2018 from different hospitals in Tehran, Iran. Antimicrobial susceptibility testing was performed according to the Clinical and Laboratory Standards Institute (CLSI) guidelines. Molecular genotyping was performed using SCCmec and accessory gene regulator (agr) typing, PVL haplotyping, multilocus sequence typing (MLST), and pulsed-field gel electrophoresis (PFGE).

Results: The highest antibiotic resistance rate was found to be against erythromycin (57.1\%), followed by ciprofloxacin (42.8\%) and clindamycin (35.7\%). Moreover, 19 (67.9\%) out of $28 \mathrm{~S}$. aureus isolates were identified as MRSA, including CA-MRSA (14/19, 73.7\%) and HA-MRSA (5/19, 26.3\%). SCCmec type IVa was detected as the predominant type $(10 / 19,52.6 \%)$, followed by type III $(5 / 19,26.3 \%)$ and type $\mathrm{V}(4 / 19,21.1 \%)$. The agr type I was identified as the most common type (14/28,50\%), and $\mathrm{H}$ and $\mathrm{R}$ haplotype groups were observed at frequencies of 67.9 and $32.1 \%$, respectively. Among $\mathrm{H}$ variants, the predominant variant was $\mathrm{H} 2$ (78/9\%). The isolates encompassed 21 different sequence types (STs), including 16 new STs (ST5147 to ST5162). Based on eBURST analysis, the isolates were clustered into five CCs, including CC30, CC22, CC1, CC8, and CC5 (ST5160), and nine singletons. PFGE typing showed that 24 isolates were clustered into A (4 pulsotypes), B (9 pulsotypes), and C (11 pulsotypes) clusters.

Conclusions: A high prevalence of PVL-positive CA-MRSA strains was detected in Iran. The majority of PVL-positive isolates were of $\mathrm{H}$ (mostly H2) variant, while $\mathrm{R}$ variant was harbored by $100 \%$ of PVL-positive MRSA strains. Also, CC8, CC22, and CC30 were identified as the dominant clones among PVL-encoding S. aureus strains. This study promotes a better understanding of the molecular epidemiology and evolution of PVL-positive $S$. aureus strains in Iran.
\end{abstract}

Keywords: Staphylococcus aureus, Panton-valentine leukocidin, Haplotype groups, MLST, PFGE, Iran

\footnotetext{
* Correspondence: b.bakhshi@modares.ac.ir

'Department of Bacteriology, Faculty of Medical Sciences, Tarbiat Modares University, Jalal-Ale-Ahmad Ave, Tehran 14117-13116, Iran

Full list of author information is available at the end of the article
}

C C The Author(s). 2021 Open Access This article is licensed under a Creative Commons Attribution 4.0 International License, which permits use, sharing, adaptation, distribution and reproduction in any medium or format, as long as you give appropriate credit to the original author(s) and the source, provide a link to the Creative Commons licence, and indicate if changes were made. The images or other third party material in this article are included in the article's Creative Commons licence, unless indicated otherwise in a credit line to the material. If material is not included in the article's Creative Commons licence and your intended use is not permitted by statutory regulation or exceeds the permitted use, you will need to obtain permission directly from the copyright holder. To view a copy of this licence, visit http://creativecommons.org/licenses/by/4.0/ The Creative Commons Public Domain Dedication waiver (http://creativecommons.org/publicdomain/zero/1.0/) applies to the data made available in this article, unless otherwise stated in a credit line to the data. 


\section{Background}

Staphylococcus aureus (S. aureus)-associated disorders vary from skin infections to life-threatening invasive diseases, such as bacteremia, sepsis, and endocarditis, mediated by a variety of virulence factors [1, 2]. S. aureus plays an important role in the development of epidural abscesses, meningitis, toxic shock syndrome (TSS), urinary tract infections (UTIs), septic thrombophlebitis, pneumonia, etc. $[3,4]$. S. aureus causes invasive infections in all age groups, but the prevalence of these infections is somewhat higher in infants and patients over 65 years of age [3]. Panton-Valentine Leukocidin (PVL) is a two-component toxin produced by some $S$. aureus strains in varying amounts $[5,6]$. However, the majority of isolates that cause skin and soft tissue infections (SSTI) and severe necrotizing pneumonia are PVLpositive [7]. This preforming toxin is encoded by a 1.9kb lukSF-PV locus consisting of two contiguous, but cotranscribed $l u k F$ and $l u k S$ genes [8]. It is well documented that these two components are secreted by $S$. aureus strains, and before they assemble into a poreforming heptamer on neutrophil membranes, they could induce lysis of host defense cells, including human polymorphonuclear neutrophils (PMNs), monocytes, and macrophages $[9,10]$. PVL causes apoptosis in neutrophils through the activation of caspase-3 and -9; the participation of TLR2 (toll like receptor 2) in causing inflammation by PVL in the lung has also been reported [4].

Generally, phages are considered as one of the major mobile genetic elements (MGEs) among $S$. aureus strains, which are strongly able to transfer antibiotic resistance markers and virulence attributes [11, 12]. The genes encoding PVL are also located on lysogenized bacteriophages integrated into the chromosomal content of $S$. aureus [9]. Currently, these phages are classified into the order Caudovirales, which could be divided into three major families based on the tail morphology, including Podoviridae, Siphoviridae, and Myoviridae [8]. To date, at least 10 PVL phages belonging to the Siphoviridae family have been identified and sequenced, including 108PVL, PVL, tp310-1, SLT, Sa2958, Sa2MW, Sa2usa, 7247PVL/ST5967PVL, TCH60, and Sa119 PVL [13-17]. They are characterized as double-stranded, non-enveloped DNA viruses with an icosahedral head and a long non-contractile tail $[5,12]$.

The emergence of PVL-positive methicillin-resistant S. aureus (PVL-MRSA) isolates have been reported worldwide [18]. Previous studies have revealed a strongassociation between the presence of PVL genes and community-associated MRSA (CA-MRSA) strains, especially those carrying staphylococcal cassette chromosomemec (SCCmec) types IV [19]. Moreover, hospitalacquired MRSA (HA-MRSA) strains that carry PVL genes have been reported in various geographical regions
inEurope and Asia [9, 19, 20]. Generally, infections caused by PVL-positive methicillin-sensitive S. aureus (PVL-MSSA) strains have been reported to play the role ofreservoirs for PVL-MRSA due to clonality and evolutionary relationships [21].

Some studies have shown an association between PVL genes and invasive diseases, implying that PVL is an epidemiological marker for severe infection syndrome; also, individuals with PVL-positive skin and soft-tissue infections are more likely to require surgery compared to those with PVL-negative infection. In some countries, this notion has led to the implementation of public health measures for individuals infected with PVLproducing strains. Compared with PVL-negative $S$. aureus, PVL-positive $S$. aureus strains are more likely to be truly community-acquired, infecting individuals who have not had contact with healthcare settings [10]. However, the potential risk of spreading PVL-positive $S$. aureus strains to hospitals is considered as a significant public health concern, as the establishment of a PVLpositive clonal lineage of HA-MRSA strains could rapidly lead to dramatically worse outcomes for HA-MRSA patients. However, there are clonal lineages from which HA-MRSA and CA-MRSA have been reported [5].

To date, at least 22 single-nucleotide polymorphisms (SNPs) have been identified in the $l u k S F-P V$ genes based on phylogenetic analysis $[8,13,22]$. Additionally, a number of non-synonymous mutations have been detected in different isoforms of PVL protein. PVL-positive S. aureus strains could be classified into four major haplotype groups ( $\mathrm{R}, \mathrm{H} 1, \mathrm{H} 2, \mathrm{H} 3)$ based on non-synonymous variations in the PVL sequence at nucleotide positions 527, 663, and 1396 [22, 23].

The population structure and clones of MRSA strains are changing in different healthcare facilities in different countries. The most prevalent PVL-MRSA types in the United States belong to ST8 (USA300), ST1 (USA400), ST59 (USA1000), and ST30 (USA1100), while ST80 clone is commonly reported in European countries [24]. Furthermore, several clones belonging to ST80, ST30, ST59, and ST22 have been reported as the most frequent clones in Asia [24-26]. Previous studies in Iran have reported ST22, ST30, ST8, ST931, ST722, ST15, ST88, ST239, ST291, and ST585 as the predominant clones among MRSA strains [27-29]

Currently, there is very limited data on the molecular epidemiology of PVL-encoding S. aureus clinical strains in Iran. In addition, no details have yet been reported about PVL haplotype groups of $S$. aureus strains in Iran. The present study aimed to obtain a more complete description about the molecular epidemiology and genetic background of PVL-positive $S$. aureus clinical strains isolated from Iranian patients using a combination of molecular typing techniques, including SCCmec and 
accessory gene regulator (agr) typing, PVL haplotyping, multilocus sequence typing (MLST) analysis, and pulsed-field gel electrophoresis (PFGE). The antibiotic susceptibility of the strains was also determined.

\section{Materials and methods Bacterial strains}

In this study $600 \mathrm{~S}$. aureus isolates were analysed and a total of 28 PVL-positive $S$. aureus strains were collected from February 2015 to March 2018 from different hospitals in Tehran, Iran. The strains were obtained from both outpatients (24 strains) and inpatients (4 strains). Clinical data and demographic information were recorded for all patients enrolled in this study using a questionnaire. All patients or their legal guardians provided their written informed consent. This study was approved by the Medical Ethics Committee of Tarbiat Modares University before it began. In addition, all methods were carried out in accordance with relevant guidelines and regulations at Tarbiat Modares University.

All S. aureus strains were identified using conventional phenotypic and biochemical examinations, including colony morphology, Gram staining, mannitol fermentation on mannitol salt agar (MSA), positive reactions in catalase, slide and tube coagulase, and DNase tests. Isolates were preserved in tryptic soy broth (TSB) with $20 \%$ glycerol (v/v) at $-80^{\circ} \mathrm{C}$.

\section{Antimicrobial susceptibility testing}

Antimicrobial susceptibility testing was performed by the Kirby-Bauer disk diffusion method according to the Clinical and Laboratory Standards Institute guidelines [31] using the following antibiotics (Mast Diagnostics, UK): chloramphenicol $(30 \mu \mathrm{g})$, amikacin $(30 \mu \mathrm{g})$, erythromycin $(15 \mu \mathrm{g})$, clindamycin $(2 \mu \mathrm{g})$, gentamicin $(10 \mu \mathrm{g})$, linezolid $(30 \mu \mathrm{g})$, ciprofloxacin $(5 \mu \mathrm{g})$, trimethoprimsulfamethoxazole $(25 \mu \mathrm{g})$, rifampicin $(5 \mu \mathrm{g})$, and cefoxitin $(30 \mu \mathrm{g})$. S. aureus ATCC 25923 was used for quality control.

\section{Genomic DNA preparation and detection of $p v /$ gene}

Genomic DNA was extracted using Gram Positive DNA Purification Kit (Gene Transfer Pishgaman, Iran) according to the manufacturer's protocol. DNA samples were evaluated in terms of quality by electrophoresis on $0.8 \%$ $(\mathrm{w} / \mathrm{v})$ agarose gels and then stored at $-20^{\circ} \mathrm{C}$ until used for PCR analysis. PCR was used to confirm the presence of $p v l$ gene in all strains using specific primers (pvl-F GGAAACATTTATTCTGGCTATAC and pvl-R CTGG ATTGAAGTTACCTCTGG), yielding a 502 bp fragment as previously described [32].

\section{Detection of MRSA strains and $\mathrm{SCCmec}$ typing}

All $S$. aureus strains in this study were screened for MRSA according to resistance to cefoxitin $(30 \mu \mathrm{g})$ using the Kirby-Bauer disk diffusion method ([33]). The identity of MRSA strains was confirmed by detection of mecA using PCR method ([33]). A multiplex PCR-based method was also carried out for SCCmec typing as previously described [32]. The oligonucleotide primers used to amplify the genes of interest are listed in Table 1.

\section{agr genotyping by multiplex PCR}

The agr types (I-IV) were determined by a multiplex PCR assay as described by Shopsin et al. [34]. The oligonucleotide primers used to amplify the genes of interest are listed in Table 1.

\section{Determination of PVL haplotype groups}

A PCR-based sequencing method was applied to determine SNPs in the lukSF-PV genes of all S. aureus strains. PCR amplifications were performed using a primer pair (lukS-F GTGGTCCATCAACAGGAGGT and lukF-R TGGTCCCCAACCATTATTCA) specifically designed to generate a $1107 \mathrm{bp}$ fragment (nucleotides 440 to 1546) of the lukSF-PV genes. PCR was carried out in a final volume of $25 \mu \mathrm{L}$ reaction mixture containing $10 \mu \mathrm{L}$ of Taq DNA Polymerase Master Mix (Ampliqon, Denmark), $0.5 \mu \mathrm{L}$ of each primer (10 pmol), and $2 \mu \mathrm{L}$ of template DNA (approximately $200 \mathrm{ng}$ ) using a thermocycler (Eppendorf, Hamburg, Germany). Amplifications were run under the following cycling conditions: an initial denaturation at $94{ }^{\circ} \mathrm{C}$ for $5 \mathrm{~min}$; followed by 30 cycles of denaturation at $94^{\circ} \mathrm{C}$ for $1 \mathrm{~min}, 57^{\circ} \mathrm{C}$ for $1 \mathrm{~min}$, and $72{ }^{\circ} \mathrm{C}$ for $1 \mathrm{~min}$; and a final elongation step at $72^{\circ} \mathrm{C}$ for $5 \mathrm{~min}$. Sanger sequencing of both strands was performed using an automated sequencer (Microsynth, Balgach, Switzerland). DNA sequences were edited by Chromas Lite software Version 2.5.1 (Technelysium Pty Ltd., Australia). The edited nucleotide sequences of $L u k S F-P V$ genes were subjected to in-frame translation using BioEdit software Version 7.2.5 and aligned to the sequence of MRSA strain USA300 (GenBank: CP000255.1) as a reference sequence.

\section{MLST}

MLST was performed for all S. aureus strains using previously reported primers specific for seven housekeeping genes, including $a r c C$, aroE, $g l p F, g m k, p t a, t p i$, and $y q i L$, according to the previously described protocol [35]. The sequences of the PCR products were compared to those of the existing alleles available on the MLST website (https://pubmlst.org/saureus/) and analyzed online to assign allelic profile (sequence type, ST) and the associated clonal complex (CC). The minimum spanning tree (MST) was constructed by the goeBURST algorithm 
Table 1 Oligonucleotide primers used in this study

\begin{tabular}{|c|c|c|}
\hline Primer & Sequence $\left(5^{\prime} \rightarrow 3^{\prime}\right)$ & Product size (bp) \\
\hline SCCmec I & $\begin{array}{l}\text { F: GCTTTAAAGAGTGTCGTTACAGG } \\
\text { R: GTTCTCTCATAGTATGACGTCC }\end{array}$ & 613 \\
\hline sccmec II & $\begin{array}{l}\text { F: CGTTGAAGATGATGAAGCG } \\
\text { R: CGAAATCAATGGTTAATGGACC }\end{array}$ & 398 \\
\hline sccmec III & $\begin{array}{l}\text { F: CCATATTGTGTACGATGCG } \\
\text { R: CCTTAGTTGTCGTAACAGATCG }\end{array}$ & 280 \\
\hline SCCmec IVa & $\begin{array}{l}\text { F: GCCTTATTCGAAGAAACCG } \\
\text { R: CTACTCTTCTGAAAAGCGTCG }\end{array}$ & 776 \\
\hline SCCmec IVb & $\begin{array}{l}\text { F: TCTGGAATTACTTCAGCTGC } \\
\text { R: AAACAATATTGCTCTCCCTC }\end{array}$ & 493 \\
\hline SCCmec IVc & $\begin{array}{l}\text { F: ACAATATTTGTATTATCGGAGAGC } \\
\text { R: TTGGTATGAGGTATTGCTGG }\end{array}$ & 200 \\
\hline SCCmec IVd & $\begin{array}{l}\text { F: CTCAAAATACGGACCCCAATACA } \\
\text { R: TGCTCCAGTAATTGCTAAAG }\end{array}$ & 881 \\
\hline sccmec V & $\begin{array}{l}\text { F: GAACATTGTTACTTAAATGAGCG } \\
\text { R: TGAAAGTTGTACCCTTGACACC }\end{array}$ & 325 \\
\hline PanF & F: ATGCACATGGTGCACATGC & \\
\hline $\operatorname{agr} 1$ & R: GTCACAAGTACTATAAGCTGCGAT & 441 \\
\hline$a g r \|$ & R: TATTACTAATTGAAAAGTGGCCATAGC & 575 \\
\hline agr III & R: GTAATGTAATAGCTTGTATAATAATACCCAG & 323 \\
\hline $\operatorname{agr}$ IV & R: CGATAATGCCGTAATACCCG & 659 \\
\hline
\end{tabular}

using PHYLOViZ 2.0 software (https://www.phyloviz. net/).

\section{PFGE}

PFGE was performed using SmaI restriction enzyme (Takara, Japan) digestion according to the protocol described by the Center for Disease Control and Prevention (CDC) with minor modifications (https://www.cdc. gov/pulsenet/pathogens/pfge.html). The chromosomal DNA of Salmonella enterica serovar Braenderup (H9182) was used as the normalization standard and molecular marker. Digested plugs were loaded into the wells of a $1 \%$ agarose gel and run in $0.5 \mathrm{X}$ TBE using a CHEF (contour-clamped homogeneous electric field)DR III system (Bio-Rad, Hercules, CA). After completing the electrophoresis process, the gel was stained using a $1.5 \mu \mathrm{g} / \mathrm{mL}$ ethidium bromide solution for 30-40 min on a rocking shaker in a covered container. Destaining was done three times with distilled water on the shaker for $45 \mathrm{~min}$, and then the gel was visualized and photographed. Gel photos were processed and analyzed using GelCompare II software V. 4.0 (Applied Maths, Saint Martens-Latem, Belgium). Similarities between electrophoretic patterns were calculated using the Dice coefficient and set to $80 \%$ to determine the pulsed-field type clusters after reviewing the epidemiologic data associated with each of the clusters of isolates. The unweighted pair group method with arithmetic means
(UPGMA) was used to construct a dendrogram with $1.5 \%$ tolerance and optimization as standard settings.

\section{Results}

Antibiotic resistance profiles

The antibiotic resistance profiles of 28 PVL-positive $S$. aureus isolates against various antibiotics are shown in Fig. 1. The highest resistance was observed against erythromycin $(16 / 28,57.1 \%)$, followed by ciprofloxacin $(12 / 28,42.8 \%)$, clindamycin $(10 / 28,35.7 \%)$, rifampicin $(9 / 28,32.1 \%)$, gentamicin $(5 / 28,17.8 \%)$, amikacin $(4 / 28$, $14.3 \%)$, and trimethoprim-sulfamethoxazole (3/28, $10.7 \%)$. The lowest resistance was observed against linezolid and chloramphenicol with the same rate $(1 / 28$, 3.6\%). Of 28 PVL-positive S. aureus isolates, 19 (67.9\%) isolates were MRSA, including CA-MRSA (14/19, 73.7\%) and HA-MRSA (5/19, 26.3\%). Among MRSA isolates, the highest resistance was observed against erythromycin (10/19, 52.6\%) and ciprofloxacin (8/19, 42.1\%). All MRSA isolates were susceptible to linezolid, and resistance to trimethoprim-sulfamethoxazole and chloramphenicol was observed in 10.5 and $5.3 \%$ of the isolates, respectively. Of 19 MRSA isolates, 5 (26.3\%) were found to be resistant to at least three tested antibiotics. Among MSSA $(9 / 28,32.1 \%)$ isolates, the highest resistance rate was observed against erythromycin and clindamycin (6/ 9, 66.7\%). All MSSA isolates were found to be susceptible to chloramphenicol and amikacin. 


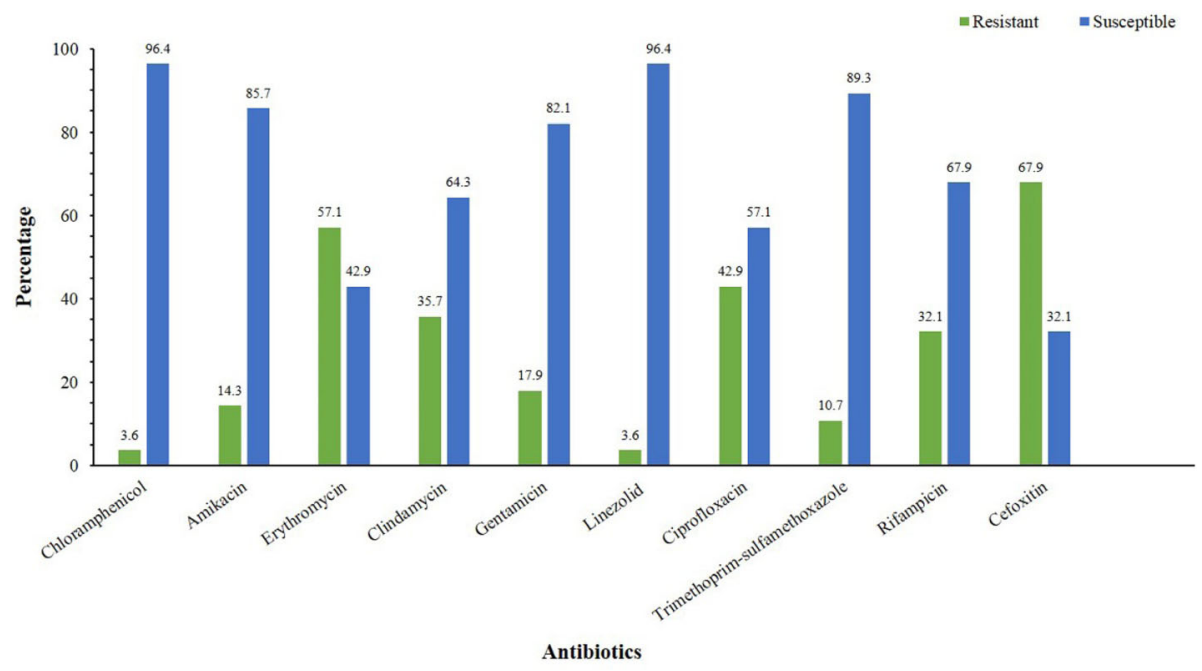

Fig. 1 Bar graph presenting antimicrobial susceptibility patterns of $28 \mathrm{PVL}$-positive S. aureus isolates in this study

\section{SCCmec and agr typing}

By SCCmec typing, only three types (types III, IVa, and V) were found among 19 PVL-positive MRSA isolates. The most common type of SCCmec was type IVa (10/ $19,52.6 \%)$, followed by type III $(5 / 19,26.3 \%)$ and type V $(4 / 19,21.1 \%)$.

The agr types of all 28 PVL-positive $S$. aureus isolates (MSSA and MRSA) indicated that agr type I was the predominant one $(14 / 28,50 \%)$, followed by type III $(10 /$ $28,35.8 \%)$, type II $(3 / 28,10.7 \%)$, and type IV $(1 / 28$, $3.5 \%)$. The detailed antibiotic resistance profile and molecular characterization of PVL-positive isolates by SCCmec, agr, haplotype, MLST, and PFGE typing are shown in Table 2.

\section{Haplotype groups}

Approximately $1107 \mathrm{bp}$ fragments of lukSF-PV genes of 28 PVL-positive $S$. aureus isolates were amplified by $\mathrm{PCR}$, and the products were sequenced. As expected, the sequences were highly conserved, but nucleotide variations were observed at seven sites (positions 470, 527, and 663 located in the lukS locus and positions 1304, 1318,1393 , and 1396 located in the lukF locus) using the lukSF-PV genes of MRSA strain USA300 as a reference. Among the isolates, 19 (67.9\%) isolates were of $\mathrm{H}$ variant, representing the most common types as defined by O'Hara et al. [22], and the remaining nine (32.1\%) isolates were identified as $\mathrm{R}$ variant, displaying nonsynonymous mutation at nucleotide 527 A to G. Also, H variants were further classified into $\mathrm{H} 1$ (4/28, 14.3\%) and $\mathrm{H} 2(15 / 28,53.6 \%)$ groups which differed in nucleotide position 1396. Furthermore, H1 variants were further divided into $\mathrm{H} 1 \mathrm{a}(n=3)$ and $\mathrm{H} 1 \mathrm{~b}(n=1)$ groups according to the differences in nucleotide sites 1304 and 1318. Additionally, $\mathrm{H} 2$ variants were grouped into $\mathrm{H} 2 \mathrm{a}$
( $n=14)$ and H2b $(n=1)$ groups according to the difference in nucleotide site 470 . The schematic structure of the lukSF-PV sequence variants found in 28 PVLpositive $S$. aureus clinical strains under study compared to the lukSF-PV sequence of USA300 strain is shown in Fig. 2. All $\mathrm{R}$ variants were MRSA, but only $50 \%$ of $\mathrm{H} 1$ variants were MRSA. Both $\mathrm{R}$ and $\mathrm{H} 1$ variants were isolated from the wound and hospitalized patients, except for one case in each variant. H2 variants were isolated from wound, blood and tracheal cultures and 53.3\% were MRSA.

\section{MLST}

The evolutionary and genetic diversity of 28 PVL-positive S. aureus isolates was analyzed by MLST (Table 2). In this study, 21 distinct STs were identified among the isolates, of which 16 STs did not have matching profiles in the MLST database and were subsequently designated to ST5147-ST5162 after submitting the data to the website (https://pubmlst.org/saureus/). Among the obtained STs, the most frequently identified one was ST30 $(6 / 28,21.4 \%)$, followed by ST1996 and ST1136, each accounted for two isolates $(2 / 28,7.1 \%)$. Other STs accounted for one isolate. ST30 was the predominant type $(6 / 19,31.6 \%)$ among MRSA isolates, while no predominant ST was found among MSSA isolates.

Based on eBURST analysis and by using all $S$. aureus STs available in the MLST database, the isolates were clustered into five CCs, including CC30 (ST30, ST5148), CC22 (ST22, ST5152, ST5153, ST5155, ST5157), CC1 (ST1136, ST5149), CC8 (ST5148, ST5156, ST5158), and CC5 (ST5160), and nine singletons (ST121, ST1996, ST5151, ST5152, ST5154, ST5159, ST5161, ST5162). The largest cluster was CC30 with seven isolates (25\%), followed by $\mathrm{CC} 22$ with five isolates $(17.9 \%)$ as well as 
Table 2 The detailed antibiotic resistance profile and molecular characterization of 28 PVL-positive S. aureus isolates by haplotype, agr, SCCMec, MLST and PFGE typing

\begin{tabular}{|c|c|c|c|c|c|c|c|c|}
\hline Haplotype group & agr type & scCmec & ST & CC & PFGE & Antibiotic resistance & lukS-PV GenBank & lukF-PV GenBank \\
\hline \multirow[t]{9}{*}{$\bar{R}$} & । & III & ST30 & CC30 & C & $A K, E, C D, G M, C I P, R I, F O X$ & MT468511 & MT468539 \\
\hline & $\|$ & V & ST30 & CC30 & C & $\mathrm{E}, \mathrm{CD}, \mathrm{CIP}, \mathrm{Rl}, \mathrm{FOX}$ & MT468512 & MT468540 \\
\hline & । & V & ST30 & CC30 & C & $E, C I P, F O X$ & MT468514 & MT468542 \\
\hline & III & IV & ST30 & CC30 & NT & $E, C I P, F O X$ & MT468515 & MT468543 \\
\hline & । & IV & ST22 & CC22 & C & FOX & MT468520 & MT468548 \\
\hline & III & IV & ST1136 & $\mathrm{CC} 1$ & C & E, FOX & MT468517 & MT468545 \\
\hline & III & IV & ST1136 & $\mathrm{CC} 1$ & C & E, FOX & MT468518 & MT468546 \\
\hline & । & IV & ST1996 & Singleton & C & FOX & MT468510 & MT468538 \\
\hline & । & IV & ST121 & Singleton & C & CIP, FOX & MT468519 & MT468547 \\
\hline \multirow[t]{4}{*}{$\mathrm{H} 1$} & । & - & ST5148 & CC30 & B & $C D, L Z D, R I$ & MT468494 & MT468522 \\
\hline & IV & III & ST5153 & $\mathrm{CC} 22$ & A & $\mathrm{E}, \mathrm{CD}, \mathrm{GM}, \mathrm{CIP}, \mathrm{RI}, \mathrm{FOX}$ & MT468499 & MT468527 \\
\hline & । & - & ST5147 & $\mathrm{CC} 8$ & B & $A K, E, C D, G M, C I P, S X T, R I$ & MT468493 & MT468521 \\
\hline & । & IV & ST5151 & Singleton & NT & FOX & MT468497 & MT468525 \\
\hline \multirow[t]{15}{*}{$\mathrm{H} 2$} & III & V & ST30 & CC30 & NT & SXT, FOX & MT468513 & MT468541 \\
\hline & III & IV & ST30 & CC30 & B & E, FOX & MT468516 & MT468544 \\
\hline & III & III & ST5150 & CC22 & C & $C, E, C I P, F O X$ & MT468496 & MT468524 \\
\hline & । & - & ST5155 & CC22 & B & $E, C D$ & MT468501 & MT468529 \\
\hline & III & III & ST5157 & CC22 & A & $A K, G M$ & MT468503 & MT468531 \\
\hline & । & III & ST5156 & $\mathrm{CC} 8$ & B & $A K, E, C D, G M, C I P, R I, S X T, F O X$ & MT468502 & MT468530 \\
\hline & III & IV & ST5158 & CC8 & C & FOX & MT468504 & MT468532 \\
\hline & । & - & ST5149 & $\mathrm{CC} 1$ & B & $E, C D, C I P, R I$ & MT468495 & MT468523 \\
\hline & $\|$ & - & ST5160 & CC5 & B & $E, C D$ & MT468506 & MT468534 \\
\hline & III & - & ST5152 & Singleton & B & $E, C D$ & MT468498 & MT468526 \\
\hline & III & - & ST5154 & Singleton & C & $\mathrm{CIP}, \mathrm{RI}$ & MT468500 & MT468528 \\
\hline & । & IV & ST5159 & Singleton & A & FOX & MT468505 & MT468533 \\
\hline & । & V & ST5161 & Singleton & NT & FOX & MT468507 & MT468535 \\
\hline & I & - & ST5162 & Singleton & B & $\mathrm{E}, \mathrm{CD}, \mathrm{CIP}, \mathrm{Rl}$ & MT468508 & MT468536 \\
\hline & $\|$ & - & ST1996 & Singleton & A & $N R$ & MT468509 & MT468537 \\
\hline
\end{tabular}

- no SCCmec elements were detected (MSSA)

NT non-typeable

$N R$ non-resistant

$\mathrm{CC} 1$ and $\mathrm{CC} 8$, each with three isolates (10.7\%). The remaining $\mathrm{CC} 5$ included one isolate. Among MRSA isolates, the predominant cluster was CC30 including $31.6 \%(6 / 19)$ of the isolates, while no predominant CC was detected among MSSA isolates. Figures 3 and 4 represent the MLST of $576 \mathrm{~S}$. aureus clones downloaded from the MLST website (105 STs) and 443 STs previously described in the literature [27-30,36-42], as well as 28 STs identified in this study, respectively.

\section{PFGE}

The genetic relationship between 28 PVL-positive $S$. aureus isolates was determined by PFGE. PFGE typing showed that 24 isolates were clustered into three PFGE clusters (A, B, and $\mathrm{C})$, and the remaining four isolates did not represent satisfactory results for typing. Most of the isolates were divided into PFGE cluster B (9 pulsotypes) and cluster $C$ (11 pulsotypes), together accounting for $62.5 \%(15 / 24)$ of the isolates. The majority of MRSA isolates $(10 / 15,66.7 \%)$ and also $\mathrm{R}$ variants $(8 / 9,88.9 \%)$ were grouped in PFGE cluster C. Additionally, most of the $\mathrm{H} 2$ variants $(7 / 12,58.3 \%)$ were grouped in PFGE cluster B. Dendrogram depicting the PFGE patterns and characteristics related to genetic background of 24 PVLpositive $S$. aureus isolates is shown in Fig. 5.

\section{Discussion}

MALDI-TOF MS-based DOT-MGA is also able to perform antimicrobial susceptibility testing within few hours, through specific novel peaks, but is applicable to 


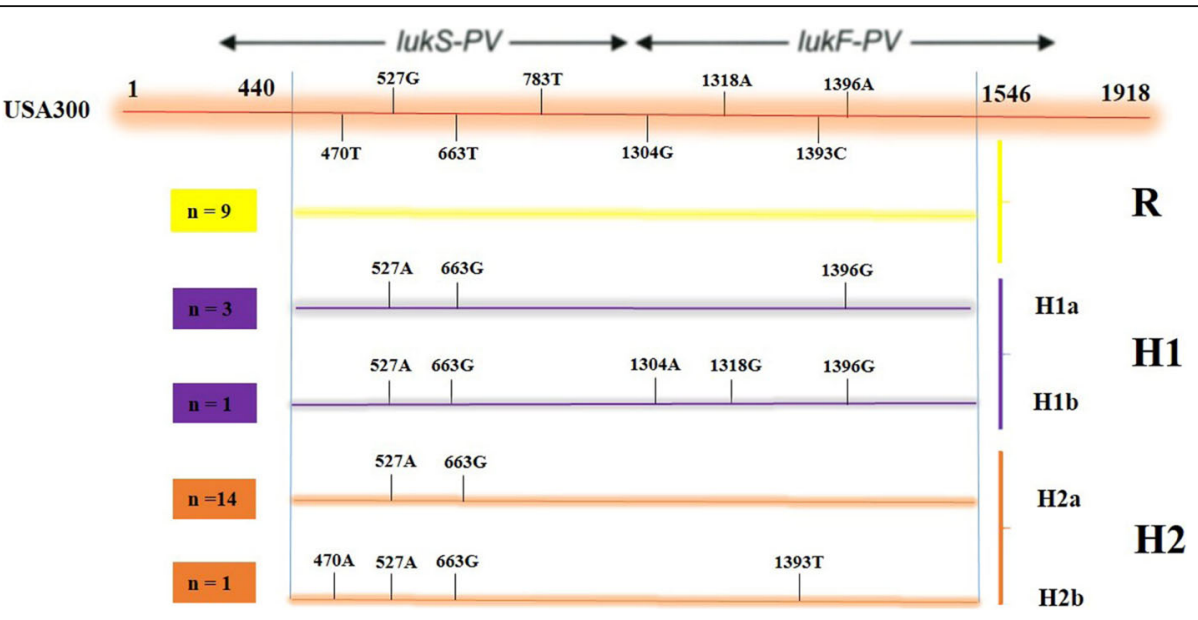

Fig. 2 Schematic structure of the lukSF-PV sequence variants detected among 28 PVL-positive S. aureus strains in this study compared to the lukSF-PV sequence of USA300 as the reference strain. Red horizontal line indicates the lukSF-PV sequence of USA300 strain. Short vertical lines on the colored lines indicate the positions of sites at which the haplotype differs from that of USA300. Numbers to the left of the horizontal lines indicate the frequency with which the haplotype $(\mathrm{R}, \mathrm{H} 1$, and $\mathrm{H} 2)$ was observed. At right, the haplotypes are bracketed according to how they are grouped into haplotype groups

only some MRSA strains [43]. Therefore, MRSA strains were detected and confirmed by targeting the mecA gene responsible for resistance in staphylococci species, located on mobile genetic element called SCCmec.

Little information is available about the predominant STs, CCs, and particularly haplotype groups of PVLpositive S. aureus strains in Iran. In the current study, attempts were made to raise awareness about the molecular relatedness and epidemiology of PVL-positive $S$. aureus strains among Iranian patients by applying a number of molecular typing techniques in this setting. In this study, the majority of the isolates $(67.85 \%)$ were detected to be PVL-positive MRSA. This result is consistent with several previous reports with respect to high prevalence of PVL-positive strains recovered from CAMRSA [44, 45]. Also, previous studies in Iran have

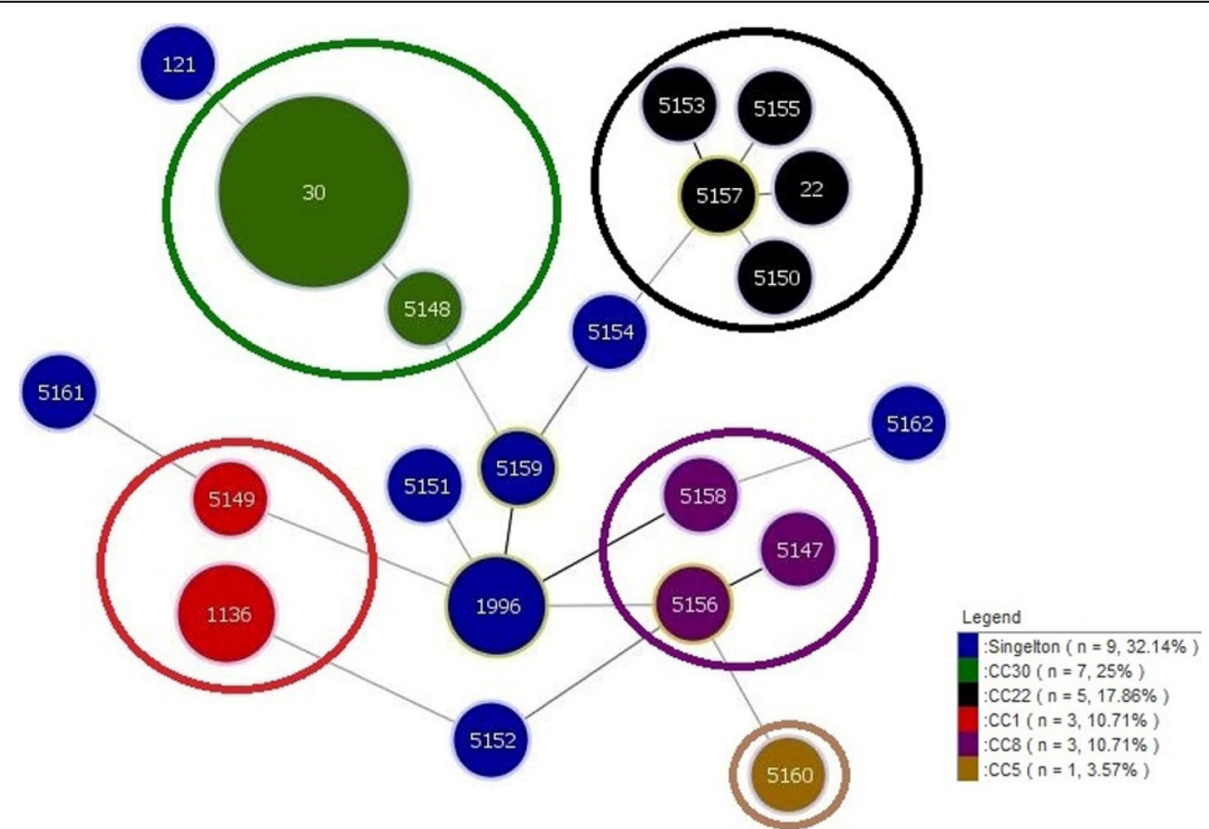

Fig. 3 The minimum spanning tree (MST) of $28 \mathrm{~S}$. aureus strains was constructed by the goeBURST algorithm using the PHYLOViZ 2.0 software (https://www.phyloviz.net/). Each circle represents a unique sequence type (ST). The size of each circle is proportional to the numbers of isolates per ST. The circles are color-coded according the clonal complex (CC) and singletons. The length between two nodes reflects the genetic distance between the two bordering STs. Similar CCs have color-coded in the legend 


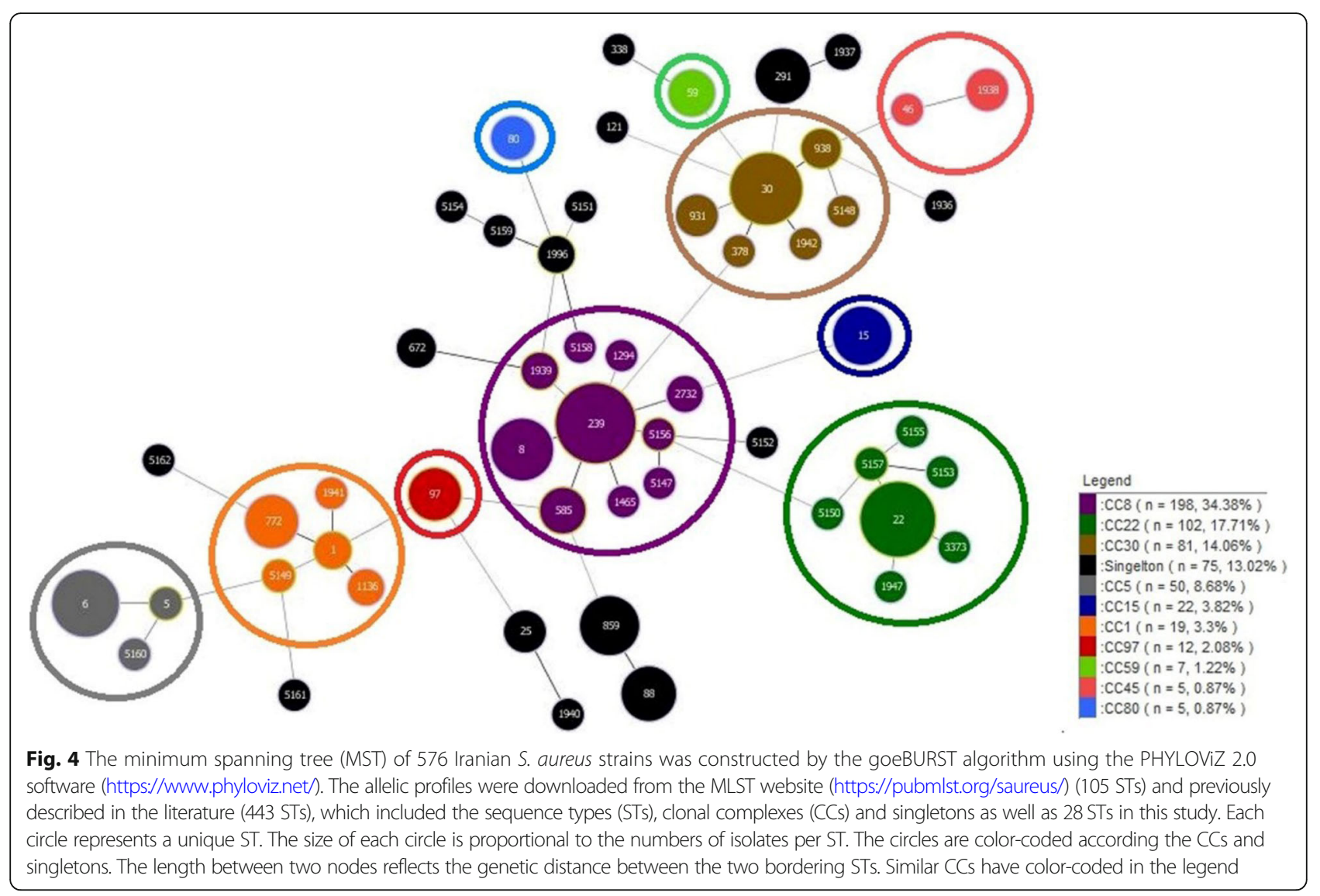

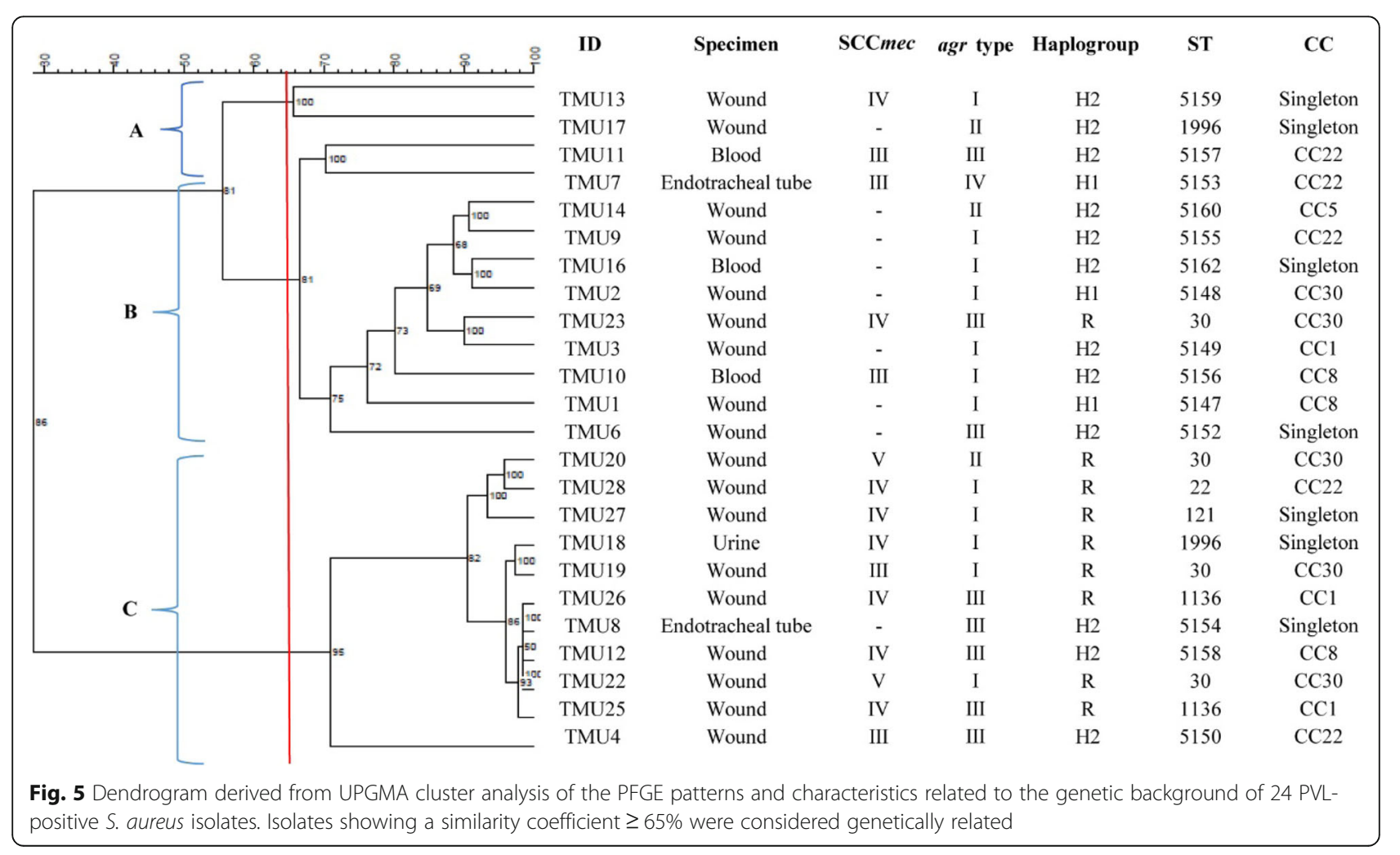


reported a high prevalence of PVL-positive strains among MRSA isolates, ranging from 12 to $60 \%$ [27, 28, 40, 42, 46].

Epidemiological studies have revealed that PVL gene is commonly carried by CA-MRSA having SCC mec type IV [47]. The majority of MRSA strains in the current $(50 \%)$ and previous studies in Iran carried SCCmec IV [30, 34, 36, 38, 41, 46, 48], supporting the hypothesize that SCCmec IV is probably more mobile than other SCCmec types. This hypothesis is further supported by the fact that most public health-associated MRSA infections reported in Iran are caused by casual transmission of CA-MRSA strains. Although PVL gene is more frequently found in CA-MRSA strains, there are some reports of PVL gene recovered from HA-MRSA strains, but with a relatively lower prevalence [31, 37]. In this study, $17.9 \%$ of PVL-positive isolates were HAMRSA. The presence of PVL gene among HA-MRSA strains and the interhospital spread of PVL encoding HA-MRSA strains support the need for system-wide implementation of patient safety and infection control initiatives.

Furthermore, PVL is carried by MSSA strains; thus, they share similar disease potential and epidemiological features with MRSA [49]. Based on most previous reports in Iran, the prevalence of PVL-positive MRSA strains is relatively higher than that of PVL-positive MSSA strains [38, 41, 50], in contrast to some European and UK countries where PVL-encoding MSSA strains are more common than PVL-positive MRSA strains [51, 52]. In agreement with most previous studies in Iran, about one third of the isolates (32.1\%) were found to be PVL-positive MSSA in this study [42, 53]. However, in our previous study [54] and the study by Havaei et al. (2017) [55], the prevalence of PVL gene in MSSA strains was higher than in MRSA strains. Therefore, further indepth studies are required to better understand the probable transfer and mobility of PVL gene among MSSA and MRSA clones.

PVL gene is highly conserved with four major variants $(\mathrm{H} 1, \mathrm{H} 2, \mathrm{H} 3, \mathrm{R})$ identified based on the sequence variations at positions 527, 663, and 1396 [23]. H1 and H2 haplotype groups are more common in India and South Africa, whereas $\mathrm{R}$ variants are frequently found in the United States [23]. $\mathrm{H}$ variant (particularly the $\mathrm{H} 2$ group) has a broader geographical distribution and spreads within several CCs such as CC22, CC30, CC1, CC5, CC8, and CC121 [23, 55]. In this study, $53.6 \%$ of the isolates carried $\mathrm{H} 2$ variants, which were distributed among five CCs (CC22, CC30, CC1, and CC5). Moreover, 32.1\% of $\mathrm{R}$ variants were allocated to three $\mathrm{CCs}$ including CC22, CC30, and CC8. There is very limited data about haplotype groups of $S$. aureus strains in Iran. In a recent study by Havaei et al. (2017), 56.6\% of S. aureus isolates had $\mathrm{H}$ variants, and $43.3 \%$ carried $\mathrm{R}$ variants [55]. Their study revealed that both $\mathrm{R}$ and $\mathrm{H}$ variants were detected among $S$. aureus strains in Iran, consistent with the present study which showed that the mecA gene was present in $52.6 \%$ of the strains belonging to $\mathrm{H}$ variants. Additionally, some studies have reported that PVLpositive MRSA strains mainly belong to $R$ variants, and only $5 \%$ of strains in $\mathrm{H}$ variants are mecA-positive [56]. In contrast, this may indicate controversial reports from different geographical locations.

It has been reported that PVL-positive MSSA and MRSA strains belong to diverse clones worldwide [49]. Although different clones were identified in this study, CC30 (31.6\%) and CC22 (21\%) were the predominant clones and PVL-positive S. aureus strains belonged to five CCs (CC30, CC22, CC8, CC1, CC5). The established four dominant MRSA clones consisted of CC30, CC22, $\mathrm{CC} 1$ and $\mathrm{CC} 80$. Two and three different SCCmec types were found in CC22 (III, IV) and CC30 (III, IV, V), respectively, and the majority of the strains $(60 \%)$ in CC22 carried SCCmec type III. Moreover, most PVL-positive CA-MRSA strains belonged to CC30, whereas most PVL-positive HA-MRSA strains belonged to CC22. As previously reported, $\mathrm{CC} 8, \mathrm{CC} 22$, and $\mathrm{CC} 30$ are the dominant clones in Iran [28, 30, 42]. PVL-positive MRSA strains belonging to CC30 have been isolated in America, Europe, Asia, and the Southwest Pacific [5759], while PVL-positive MRSA strains belonging to CC22 have been reported in England, Saudi Arabia, Germany, Ireland, Australia, and Nepal [58, 60, 61]. However, both $\mathrm{CC} 22$ and $\mathrm{CC} 30$ clones have been reported to be predominant in Asian countries [58, 62]. Based on the previous reports and also this study, it could be concluded that the most prevalent CA-MRSA clones in Asian countries including Iran are CC22 and CC30 clones $[63,64]$. The predominance of $\mathrm{CC} 22$ and CC30 clones among PVL-positive MRSA strains in Iran is of great concern, as these clones appear to be highly transmissible with a propensity to spread worldwide. In the present study, $10.7 \%$ of $S$. aureus strains were related to CC8, and only one of them had SCCmec IV and was assigned to $\mathrm{H} 2$ variant. PVL-positive MRSA strains with CC8 and SCCmec IV have been previously reported in Iran [65]. CC8 is one of the most prevalent CCs worldwide and mainly contains nosocomial epidemic MRSA isolates [66]. The highest antibiotic resistance was observed in one PVL-positive HA-MRSA strain belonging to CC8. ST8 SCCmec type IV (USA300 clone) is the predominant clone in the United States but has also been reported in other countries including Anglophone, Pakistan, UK, and some of the Gulf States countries [67]. CC1 was another CC that was detected among PVL-positive strains in this study, accounting for $66.7 \%$ of $\mathrm{R}$ variant. According to the previous studies results, $\mathrm{R}$ 
variant of PVL is mainly found in CC1, CC8, and CC93 strains [68]. The present study results showed that $\mathrm{R}$ variant was harbored by $100 \%$ of PVL-positive MRSA strains primarily belonging to $\mathrm{CC} 30$, followed by $\mathrm{CC} 1$ and $\mathrm{CC} 5$, which were different from those $\mathrm{CCs}(\mathrm{CC} 8$, CC1, and CC93) reported in previous studies $[23,55$, 69]. This finding supports the findings of previous studies in Iran, in which $\mathrm{CC} 30, \mathrm{CC} 22, \mathrm{CC} 8$, and $\mathrm{CC} 1$ were detected as the predominant CCs among PVL-positive isolates [29].

In this study, the majority of the isolates (50\%) belonged to agr type I. The agr locus belongs to the core variable genome and thus is linked to CCs. The agr typing results were consistent with the findings of previous studies in Iran and China [46, 47, 70]. In the current study, agr I and $a g r$ III were detected as the most common types and were linked to $\mathrm{CC} 30, \mathrm{CC} 22, \mathrm{CC} 8$, and CC1.

PFGE showed a high degree of genetic diversity among PVL-positive $S$. aureus clones and clustered them into A-C clusters and represented 24 PFGE pulsotypes. All R variants of PVL-positive MRSA strains belonged to cluster $\mathrm{C}$, but $\mathrm{H} 2$ variants of these strains were distributed in all three clusters, supporting the hypothesis that $\mathrm{H} 2$ groups may display higher genetic diversity than other haplotype groups. This considerable diversity in PVLpositive MRSA strains could be explained by the possibility of isolating MRSA from different sources. Application of genotyping methods such as PFGE may provide a better interpretation of MRSA transmission sources and also help adopt well-intended infection prevention and control measures.

\section{Conclusion}

To the best of our knowledge, this is the first comprehensive study investigating the molecular epidemiology and characteristics of PVL-encoding S. aureus clinical strains in Iran using several typing methods. The findings revealed i) a high prevalence of PVL-positive MRSA strains in Iran, ii) the majority of MRSA strains in the current study carried SCCmec IV, iii) both $\mathrm{R}$ and $\mathrm{H}$ variants were detected among $S$. aureus strains in Iran, iv) the mecA gene was present in $52.6 \%$ of the strains with $\mathrm{H}$ variants, v) $\mathrm{CC} 8, \mathrm{CC} 22$, and $\mathrm{CC} 30$ were found as the dominant clones among PVL-encoding $S$. aureus strains, vi) $a g r$ I and $a g r$ III were detected as the most common types and were linked to $\mathrm{CC} 30, \mathrm{CC} 22, \mathrm{CC} 8$, and $\mathrm{CC} 1$. The most important limitation of the present work was the relatively small sample size, because of low prevalence of MRSA strains. Taken together, the present study results may contribute to the understanding of the molecular epidemiology and evolution of PVL-positive S. aureus in Iran.

\section{Acknowledgements}

The current study was supported by Faculty of Medical Sciences, Tarbiat Modares University, Tehran, Iran.

\section{Authors' contributions}

ZNO performed the microbiological experiments, molecular tests, and data analysis; SNP contributed to study design, and conceptualization; AY and ZNO wrote the manuscript draft; AY, SNP and BB critically revised the manuscript. All authors approved the final version of the manuscript and authorship.

\section{Funding}

This work was supported by the Faculty of Medical Sciences, Tarbiat Modares University, Tehran, Iran.

\section{Availability of data and materials}

The partial nucleotide sequences of LuKSF-PV genes of 28 strains generated and/or analyzed during the current study are available in the GenBank/NCBI database (https://www.ncbi.nlm.nih.gov/genbank) under the following accession numbers: MT468493-MT468548.

\section{Declarations}

\section{Ethics approval and consent to participate}

This study was reviewed and approved by the Medical Ethics Committee of Tarbiat Modares University, Tehran, Iran.

\section{Consent for publication}

Not applicable.

\section{Competing interests}

The authors declare that they have no competing interests.

\section{Author details}

${ }^{1}$ Department of Bacteriology, Faculty of Medical Sciences, Tarbiat Modares University, Jalal-Ale-Ahmad Ave, Tehran 14117-13116, Iran. ${ }^{2}$ Foodborne and Waterborne Diseases Research Center, Research Institute for

Gastroenterology and Liver Diseases, Shahid Beheshti University of Medical Sciences, Tehran, Iran.

Received: 22 November 2020 Accepted: 8 April 2021

Published online: 21 April 2021

References

1. Bien J, Sokolova O, Bozko P. Characterization of virulence factors of Staphylococcus aureus: novel function of known virulence factors that are implicated in activation of airway epithelial proinflammatory response. J Pathog. 2011:1-13. https://doi.org/10.4061/2011/601905.

2. Turner NA, Sharma-Kuinkel BK, Maskarinec SA, Eichenberger EM, Shah PP, Carugati M, Holland TL, Fowler Jr VG Methicillin-resistant Staphylococcus aureus: an overview of basic and clinical research. Nat Rev Microbiol 2019; 17(4):203-218. PubMed PMID: 30737488. Pubmed Central PMCID: PMC693 9889. Epub 2019/02/10. eng, DOl: https://doi.org/10.1038/s41579-018-014 7-4.

3. Gajdács M. The continuing threat of methicillin-resistant Staphylococcus aureus. Antibiotics. 2019;8(2):52. https://doi.org/10.3390/antibiotics8020052.

4. Yoong P, Pier GB. Immune-activating properties of Panton-valentine leukocidin improve the outcome in a model of methicillin-resistant Staphylococcus aureus pneumonia. Infect Immun. 2012;80(8):2894-904. https://doi.org/10.1128/IAl.06360-11.

5. Darboe S, Dobreniecki S, Jarju S, Jallow M, Mohammed NI, Wathuo M, et al. Prevalence of Panton-valentine leukocidin (PVL) and antimicrobial resistance in community-acquired clinical Staphylococcus aureus in an urban Gambian hospital: a 11-year period retrospective pilot study. Front Cell Infect Microbiol. 2019;9:170. https://doi.org/10.3389/fcimb.2019.00170.

6. Tajik S, Najar-Peerayeh S, Bakhshi B. Hospital clones of Panton-Valentine leukocidin positive and methicillin-resistant Staphylococcus aureus are circulating in the community of Tehran. Journal of Global Antimicrobial Resistance. 2019.

7. Shallcross LJ, Williams K, Hopkins S, Aldridge RW, Johnson AM, Hayward AC. Panton-valentine leukocidin associated staphylococcal disease: a cross- 
sectional study at a London hospital, England. Clin Microbiol Infect 2010; 16(11):1644-1648. PubMed PMID: 20969671. Epub 2010/10/26. eng, DOl: https://doi.org/10.1111/j.1469-0691.2010.03153.x.

8. Zhao H, Hu F, Jin S, Xu X, Zou Y, Ding B, et al. Typing of Panton-valentine leukocidin-encoding phages and lukSF-PV gene sequence variation in Staphylococcus aureus from China. Front Microbiol. 2016;7:1200

9. Alonzo F III, Torres VJ. Bacterial survival amidst an immune onslaught: the contribution of the Staphylococcus aureus Leukotoxins. PLoS Pathog. 2013; 9(2):e1003143. https://doi.org/10.1371/journal.ppat.1003143.

10. Shallcross LJ, Fragaszy E, Johnson AM, Hayward AC. The role of the Pantonvalentine leucocidin toxin in staphylococcal disease: a systematic review and meta-analysis. Lancet Infect Dis. 2013;13(1):43-54. https://doi.org/10.101 6/S1473-3099(12)70238-4.

11. Moon BY, Park JY, Hwang SY, Robinson DA, Thomas JC, Fitzgerald JR, et al. Phage-mediated horizontal transfer of a Staphylococcus aureus virulenceassociated genomic island. Sci Rep. 2015 2015/04/20; 5(1): 9784

12. Xia G, Wolz C. Phages of Staphylococcus aureus and their impact on host evolution. Infect Genet Evol 2014 Jan;21:593-601. PubMed PMID: 23660485. Epub 2013/05/11. eng, DOl: https://doi.org/10.1016/j.meegid.2013.04.022.

13. Boakes E, Kearns A, Ganner M, Perry C, Hill R, Ellington M. Distinct bacteriophages encoding Panton-valentine leukocidin (PVL) among international methicillin-resistant Staphylococcus aureus clones harboring PVL. J Clin Microbiol. 2011;49(2):684-92. https://doi.org/10.1128/JCM.01917-10.

14. Narita S, Kaneko J, Chiba J-I, Piémont Y, Jarraud S, Etienne J, et al. phage conversion of Panton-valentine leukocidin in Staphylococcus aureus: molecular analysis of a PVL-converting phage, $\varphi S L T$. Gene. 2001;268(1-2): 195-206. https://doi.org/10.1016/S0378-1119(01)00390-0.

15. Kaneko J, Kimura T, Narita S, Tomita T, Kamio Y. Complete nucleotide sequence and molecular characterization of the temperate staphylococcal bacteriophage $\varphi P V L$ carrying Panton-valentine leukocidin genes. Gene. 1998;215(1):57-67. https://doi.org/10.1016/S0378-1119(98)00278-9.

16. Kaneko J, Kimura T, Kawakami Y, Tomita T, Kamio Y. Panton-valentine leukocidin genes in a phage-like particle isolated from mitomycin C-treated Staphylococcus aureus V8 (ATCC 49775). Biosci Biotechnol Biochem. 1997; 61(11):1960-2. https://doi.org/10.1271/bbb.61.1960.

17. Zhang M, Ito T, Li S, Jin J, Takeuchi F, Lauderdale TL, et al. Identification of the third type of PVL phage in ST59 methicillin-resistant Staphylococcus aureus (MRSA) strains. FEMS Microbiol Lett 2011; 323(1):20-28. PubMed PMID: 21732964. Epub 2011/07/08. eng, DOI: https://doi.org/10.1111/j.15746968.2011.02355.x

18. Enany S, Yaoita E, Yoshida Y, Enany M, Yamamoto T. Molecular characterization of Panton-valentine leukocidin-positive communityacquired methicillin-resistant Staphylococcus aureus isolates in Egypt. Microbiol Res. 2010;165(2):152-62. https://doi.org/10.1016/j.micres.2009. 03.005 .

19. Nicole A, Lutz J, Peter S, Ralf E, Stefan M, Paul J. Planet. Clonal Replacement of Epidemic Methicillin-Resistant Staphylococcus aureus Strains in a German University Hospital over a Period of Eleven Years. PLOS ONE. 2011;6(11): e28189.

20. Boswihi SS, Udo EE, Monecke S, Mathew B, Noronha B, Verghese T, et al. Emerging variants of methicillin-resistant Staphylococcus aureus genotypes in Kuwait hospitals. PLOS ONE. 2018;13(4):e0195933.

21. Otokunefor K, Sloan T, Kearns AM, James R. Molecular characterization and Panton-valentine leucocidin typing of community-acquired methicillinsensitive Staphylococcus aureus clinical isolates. J Clin Microbiol. 2012;50(9): 3069-72. https://doi.org/10.1128/JCM.00602-12.

22. Chen L, Chavda KD, Solanki M, Mediavilla JR, Mathema B, Schlievert PM, et al. Genetic variation among Panton-valentine leukocidin-encoding bacteriophages in Staphylococcus aureus clonal complex 30 strains. J Clin Microbiol. 2013;51(3):914-9. https://doi.org/10.1128/JCM.03015-12.

23. O'Hara FP, Guex N, Word JM, Miller LA, Becker JA, Walsh SL, et al. A geographic variant of the Staphylococcus aureus Panton-valentine leukocidin toxin and the origin of community-associated methicillinresistant S. aureus USA300. J Infect Dis. 2008;197(2):187-94. https://doi.org/1 $0.1086 / 524684$

24. Tristan A, Bes M, Meugnier H, Lina G, Bozdogan B, Courvalin P, et al. Global distribution of Panton-valentine leukocidin-positive methicillin-resistant Staphylococcus aureus, 2006. Emerg Infect Dis. 2007;13(4):594-600. https:// doi.org/10.3201/eide1304.061316.

25. Xiao N, Yang J, Duan N, Lu B, Wang L. Community-associated Staphylococcus aureus PVL+ ST22 predominates in skin and soft tissue infections in Beijing, China. Infect Drug Resist. 2019;12:2495-503. https://doi. org/10.2147/IDR.S212358

26. Wang X, Liu Q, Zhang H, Li X, Huang W, Fu Q, et al. Molecular characteristics of community-associated Staphylococcus aureus isolates from pediatric patients with bloodstream infections between 2012 and 2017 in Shanghai, China. Front Microbiol. 2018;9:1211. https://doi.org/10.33 89/fmicb.2018.01211.

27. Goudarzi M, Bahramian M, Tabrizi MS, Udo EE, Figueiredo AMS, Fazeli M, et al. Genetic diversity of methicillin resistant Staphylococcus aureus strains isolated from burn patients in Iran: ST239-SCCmec III/t037 emerges as the major clone. Microb Pathog. 2017;105:1-7. https://doi.org/10.1016/j.micpa th.2017.02.004.

28. Mirzaee M, Najar-Peerayeh S, Behmanesh M, Moghadam MF. Relationship between adhesin genes and biofilm formation in vancomycin-intermediate Staphylococcus aureus clinical isolates. Curr Microbiol. 2015;70(5):665-70. https://doi.org/10.1007/s00284-014-0771-9.

29. Goudarzi M, Navidinia M, Beiranvand E, Goudarzi H. Phenotypic and molecular characterization of methicillin-resistant Staphylococcus aureus clones carrying the Panton-valentine leukocidin genes disseminating in Iranian hospitals. Microb Drug Resist. 2018;24(10):1543-51. https://doi.org/1 0.1089/mdr.2018.0033

30. Solmaz Ohadian Moghadam, Mohammad Reza Pourmand, Mahmood Mahmoudi, Hooman Sadighian. Molecular characterization of methicillinresistant Staphylococcus aureus: characterization of major clones and emergence of epidemic clones of sequence type (ST) 36 and ST 121 in Tehran, Iran. FEMS Microbiology Letters 2015;362(8):fnv043.

31. Clinical ILPsfastoab. informational supplement: Clinical and Laboratory Standards Institute (CLSI). 2019.

32. Azimian A, Havaei SA, Fazeli H, Naderi M, Ghazvini K, Samiee SM, et al. Genetic characterization of a vancomycin-resistant Staphylococcus aureus isolated from respiratory tract of a hospitalized patient in a university hospital in north east of Iran. J Clin Microbiol. 2012:JCM. 01727-01712.

33. Tajik S, Najar-Peerayeh S, Bakhshi B, Golmohammadi R. Molecular characterization of community-associated methicillin-resistant Staphylococcus aureus in Iranian burn patients. Iran J Pathol. 2019;14(4): 284-9. https://doi.org/10.30699/IJP.2019.94189.1917.

34. Shopsin B, Mathema B, Alcabes P, Said-Salim B, Lina G, Matsuka A, et al. Prevalence of agr specificity groups among Staphylococcus aureus strains colonizing children and their guardians. J Clin Microbiol. 2003;41(1):456-9. https://doi.org/10.1128/JCM.41.1.456-459.2003.

35. Enright MC, Day NP, Davies CE, Peacock SJ, Spratt BG. Multilocus sequence typing for characterization of methicillin-resistant and methicillin-susceptible clones ofStaphylococcus aureus. J Clin Microbiol. 2000;38(3):1008-15. https://doi.org/10.1128/JCM.38.3.1008-1015.2000.

36. Goudarzi M, Goudarzi H, Figueiredo AMS, Udo EE, Fazeli M, Asadzadeh M, et al. Molecular characterization of methicillin resistant Staphylococcus aureus strains isolated from intensive care units in Iran: ST22-SCCmec IV/ t790 emerges as the major clone. PLoS One. 2016;11(5):e0155529. https:// doi.org/10.1371/journal.pone.0155529.

37. Besharati R, Ghafouri M, Safamanesh S, Khosrojerdi M, Ghazvini K, Nojumi S, et al. Molecular epidemiology of panton-valentine leukocidin harboring hospital-associated methicillin-resistant Staphylococcus aureus in septicemic children, Northeastern Iran, Bojnurd. Jundishapur J Microbiol. 2019;12(2). e68183.

38. Japoni-Nejad A, Rezazadeh M, Kazemian H, Fardmousavi N, van Belkum A, Ghaznavi-Rad E. Molecular characterization of the first community-acquired methicillin-resistant Staphylococcus aureus strains from Central Iran. Int J Infect Dis. 2013;17(11):e949-e54. https://doi.org/10.1016/j.ijid.2013.03.023.

39. Ziasistani M, Shakibaie MR, Kalantar-Neyestanaki D. Genetic characterization of two vancomycin-resistant Staphylococcus aureus isolates in Kerman, Iran. Infect Drug Resist. 2019;12:1869-75. https://doi.org/10.2147/IDR.S205596.

40. Sobhanipoor MH, Ahmadrajabi R, Karmostaji A, Saffari F. Molecular characterization of nasal methicillin resistant Staphylococcus aureus isolates from workers of an automaker company in Southeast Iran. Apmis. 2017. 125(10):921-6. https://doi.org/10.1111/apm.12732.

41. Havaei SA, Azimian A, Fazeli H, Naderi M, Ghazvini K, Samiee SM, et al. Isolation of Asian endemic and livestock associated clones of methicillin resistant Staphylococcus aureus from ocular samples in northeastern Iran. Iran J Microbiol. 2013;5(3):227-32

42. Havaei SA, Vidovic S, Tahmineh N, Mohammad K, Mohsen K, Starnino S, et al. Epidemic methicillin-susceptible Staphylococcus aureus lineages are 
the main cause of infections at an Iranian university hospital. J Clin Microbiol. 2011;49(11):3990-3. https://doi.org/10.1128/JCM.05445-11.

43. Nix ID, Idelevich EA, Storck LM, Sparbier K, Drews O, Kostrzewa M, et al. Detection of methicillin resistance in Staphylococcus aureus from agar cultures and directly from positive blood cultures using MALDI-TOF mass spectrometry-based direct-on-target microdroplet growth assay. Front Microbiol. 2020;11:232. https://doi.org/10.3389/fmicb.2020.00232.

44. Quadri SA, Al-Sultan AA, Al-Ramdan AM, Badger-Emeka LI, Ali SI. Frequency of panton-valentine leukocidin gene among clinical isolates of methicillinresistant staphylococcus aureus in Eastern Province of Saudi Arabia. J Global Infect Dis. 2020;12(1):37-8. https://doi.org/10.4103/jgid.jgid_27_19.

45. Thabit AG, Ahmed EH, Mohamed Al, Yassin AS, Ibrahim MĀ, Amin MM. Molecular detection of Panton-valentine Leukocidin (PVL) and methicillin resistance in Staphylococcus aureus pathogen. Egypt J Med Microbiol. 2017; 38(5793):1-6.

46. Zhao C, Liu Y, Zhao M, Liu Y, Yu Y, Chen H, et al. Characterization of community acquired Staphylococcus aureus associated with skin and soft tissue infection in Beijing: high prevalence of PVL+ ST398. PLoS One. 2012; 7(6):e38577. https://doi.org/10.1371/journal.pone.0038577.

47. Ghasemian A, Peerayeh SN, Bakhshi B, Mirzaee M. Detection of accessory gene regulator groups genes and cassette chromosome mec types among Staphylococcus aureus isolated from intensive care unit patients. Asian Pac J Trop Dis. 2015;5(2):153-7. https://doi.org/10.1016/S2222-1808(14)60643-5.

48. Gökmen TG, Kalayci Y, Yaman A, Köksal F. Molecular characterization of methicillin-resistant Staphylococcus aureus strains by spa typing and pulsed field gel electrophoresis methods. BMC Microbiol. 2018;18(1):155. https://doi. org/10.1186/s12866-018-1305-6.

49. Sanchini A, Del Grosso M, Villa L, Ammendolia MG, Superti F, Monaco M, et al. Typing of Panton-valentine leukocidin-encoding phages carried by methicillin-susceptible and methicillin-resistant Staphylococcus aureus from Italy. Clin Microbiol Infect. 2014;20(11):O840-O6. https://doi.org/10.1111/14 69-0691.12679.

50. Moghadam SO, Yaghooti MM, Pourramezan N, Pourmand MR. Molecular characterization and antimicrobial susceptibility of the CA-MRSA isolated from healthcare workers, Tehran, Iran. Microbial Pathog. 2017;107:409-12. https://doi.org/10.1016/j.micpath.2017.04.027.

51. Tinelli M, Monaco M, Vimercati M, Ceraminiello A, Pantosti A. Methicillinsusceptible Staphylococcus aureus in skin and soft tissue infections, Northern Italy. Emerg Infect Dis. 2009;15(2):250-7. https://doi.org/10.3201/ eid1502.080010.

52. Romano-Bertrand S, Filleron A, Mesnage R, Lotthé A, Didelot MN, Burgel L, et al. Staphylococcus aureus in a neonatal care center: methicillinsusceptible strains should be a main concern. Antimicrob Resist Infect Control. 2014;3(1):21. https://doi.org/10.1186/2047-2994-3-21.

53. Khosravi AD, Hoveizavi $H$, Farshadzadeh Z. The prevalence of genes encoding leukocidins in Staphylococcus aureus strains resistant and sensitive to methicillin isolated from burn patients in Taleghani hospital, Ahvaz, Iran. Burns. 2012;38(2):247-51. https://doi.org/10.1016/j.burns.2011.08. 002.

54. Tajik S, Najar-Peerayeh S, Bakhshi B. Hospital clones of Panton-valentine leukocidin-positive and methicillin-resistant Staphylococcus aureus circulating in the Tehran community. J Glob Antimicrobial Resist. 2020;22: 177-81. https://doi.org/10.1016/j.jgar.2019.12.010.

55. Havaei SA, Poursina F, Ahmadpour M, Havaei SR, Ruzbahani M. Detection of Panton-valentine Leukocidin gene isoforms of Staphylococcus aureus isolates in Al-Zahra Hospital, Isfahan-Iran. Adv Biomed Res. 2017:6.

56. Dumitrescu O, Tristan A, Meugnier H, Bes M, Gouy M, Etienne J, et al. Polymorphism of the Staphylococcus aureus Panton-valentine leukocidin genes and its possible link with the fitness of community-associated methicillin-resistant S. aureus. J Infect Dis. 2008;198(5):792-4. https://doi. org/10.1086/590914.

57. Boswihi SS, Udo EE, Al-Sweih N. Shifts in the clonal distribution of methicillin-resistant Staphylococcus aureus in Kuwait hospitals: 1992-2010. PLoS One. 2016;11(9):e0162744. https://doi.org/10.1371/journal.pone.0162744.

58. Monecke S, Coombs G, Shore AC, Coleman DC, Akpaka P, Borg M, et al. A field guide to pandemic, epidemic and sporadic clones of methicillinresistant Staphylococcus aureus. PLoS One. 2011;6(4):e17936. https://doi. org/10.1371/journal.pone.0017936.

59. Andrade-Figueiredo M, Leal-Balbino TC. Clonal diversity and epidemiological characteristics of Staphylococcus aureus: high prevalence of oxacillinsusceptible mecA-positive Staphylococcus aureus (OS-MRSA) associated with clinical isolates in Brazil. BMC Microbiol. 2016;16(1):115. https://doi. org/10.1186/s12866-016-0733-4.

60. Senok A, Somily A, Raji A, Gawlik D, Al-Shahrani F, Baqi S, et al. Diversity of methicillin-resistant Staphylococcus aureus CC22-MRSA-IV from Saudi Arabia and the Gulf region. Int J Infect Dis. 2016;51:31-5. https://doi.org/10.1016/j. ijid.2016.08.016.

61. Brown ML, O'Hara FP, Close NM, Mera RM, Miller LA, Suaya JA, et al. Prevalence and sequence variation of Panton-valentine leukocidin in methicillin-resistant and methicillin-susceptible Staphylococcus aureus strains in the United States. J Clin Microbiol. 2012;50(1):86-90. https://doi. org/10.1128/JCM.05564-11.

62. Song J-H, Hsueh P-R, Chung DR, Ko KS, Kang C-I, Peck KR, et al. Spread of methicillin-resistant Staphylococcus aureus between the community and the hospitals in Asian countries: an ANSORP study. J Antimicrob Chemother. 2011;66(5):1061-9. https://doi.org/10.1093/jac/dkr024.

63. Goudarzi M, Kobayashi N, Dadashi M, Pantůček R, Nasiri MJ, Fazeli M, et al. Prevalence, genetic diversity, and temporary shifts of inducible clindamycin resistance Staphylococcus aureus clones in Tehran, Iran: a molecularepidemiological analysis from 2013 to 2018. Front Microbiol. 2020;11. https://doi.org/10.3389/fmicb.2020.00663.

64. Stefani S, Chung DR, Lindsay JA, Friedrich AW, Kearns AM, Westh $H$, et al. Meticillin-resistant Staphylococcus aureus (MRSA): global epidemiology and harmonisation of typing methods. Int J Antimicrob Agents. 2012;39(4):27382. https://doi.org/10.1016/j.ijantimicag.2011.09.030.

65. Azimian A, Havaei SA, Khosrojerdi M, Naderi M, Samiee S. Isolation of PVL/ ACME-positive, community acquired, methicillin-resistant Staphylococcus aureus (USA300) from Iran. J Med Microbiol Infect Dis. 2014;2(3):100-4.

66. Liu Y, Wang H, Du N, Shen E, Chen H, Niu J, et al. Molecular evidence for spread of two major methicillin-resistant Staphylococcus aureus clones with a unique geographic distribution in Chinese hospitals. Antimicrob Agents Chemother. 2009;53(2):512-8. https://doi.org/10.1128/AAC.00804-08.

67. Jamil B, Gawlik D, Syed MA, Shah AA, Abbasi SA, Müller E, et al. Hospitalacquired methicillin-resistant Staphylococcus aureus (MRSA) from Pakistan: molecular characterisation by microarray technology. Eur J Clin Microbiol Infect Dis. 2018;37(4):691-700. https://doi.org/10.1007/s10096-017-3161-y.

68. Zhang C, Guo Y, Chu X. In vitro generation of Panton-valentine leukocidin (PVL) in clinical methicillin-resistant Staphylococcus aureus (MRSA) and its correlation with PVL variant, clonal complex, infection type. Sci Rep. 2018; $8(1): 1-7$.

69. Tong SY, Lilliebridge RA, Holt DC, Coombs GW, Currie BJ, Giffard PM. Rapid detection of $\mathrm{H}$ and $\mathrm{R}$ Panton-valentine leukocidin isoforms in Staphylococcus aureus by high-resolution melting analysis. Diagn Microbiol Infect Dis. 2010;67(4):399-401. https://doi.org/10.1016/j.diagmicrobio.2010. 03.015 .

70. Azimian A, Najar-Pirayeh S, Mirab-Samiee S, Naderi M. Occurrence of methicillin resistant Staphylococcus aureus (MRSA) among clinical samples in Tehran-Iran and its correlation with polymorphism of specific accessory gene regulator (AGR) groups. Braz J Microbiol. 2012;43(2):779-85. https://doi. org/10.1590/S1517-83822012000200043.

\section{Publisher's Note}

Springer Nature remains neutral with regard to jurisdictional claims in published maps and institutional affiliations.

Ready to submit your research? Choose BMC and benefit from:

- fast, convenient online submission

- thorough peer review by experienced researchers in your field

- rapid publication on acceptance

- support for research data, including large and complex data types

- gold Open Access which fosters wider collaboration and increased citations

- maximum visibility for your research: over $100 \mathrm{M}$ website views per year

At BMC, research is always in progress.

Learn more biomedcentral.com/submissions 